\section{El consenso en la ciudad post-política. Empresas inmobiliarias y gobiernos locales en la construcción masiva de vivienda en la periferia de la Ciudad de México}

\author{
Luis Alberto Salinas Arreortua \\ ORCID: https://orcid.org/0000-0002-0983-3629 \\ Correo electrónico: Isalinas@comunidad.unam.mx
}

\section{The consensus in the post-political city. Real estate companies and local governments in the massive construction of housing in the periphery of Mexico City}

\author{
Lisette Soto Delgado \\ ORCID: https://orcid.org/0000-0002-1482-7012 \\ Doctorante en Geografía
}

Filiación institucional: Universidad Nacional Autónoma de México, Ciudad de México, México.

\begin{abstract}
Resumen
¿Las políticas de vivienda son diseñadas para mantener un orden social y no para atender los verdaderos problemas habitacionales? A partir de una reflexión acerca del concepto de post-política, entendida como la negociación de intereses que alcanza un acuerdo que adquiere la forma de consenso, se analiza la política de vivienda en México y, de manera particular, las implicaciones a nivel local de los acuerdos para los procesos de autorización de conjuntos urbanos en municipios de la Zona Metropolitana del Valle de México. Esto se realiza a la luz de documentos internacionales y locales sobre la materia, así como a través de entrevistas semiestructuradas a funcionarios públicos de los gobiernos municipales y estatales. Se concluye que el consenso postpolítico se construye a partir de dos dimensiones: por un lado, mediante la normativa impuesta por parte de organismos internacionales y del gobierno federal y, por otro, a partir de las tensiones entre los distintos niveles de gobierno y las empresas inmobiliarias. De esta manera, el consenso de la post-política se puede entender desde la superposición de discursos y prácticas en diferentes niveles, en donde se excluye tanto la posibilidad de cuestionar la política como los proyectos políticos en torno a la producción de vivienda.
\end{abstract}

Palabras clave

Ciudad de México, ciudad post-política, consenso, política de vivienda

\begin{abstract}
Are housing policies designed to maintain social order and not address real housing problems? Starting with a reflection on the concept of post-politics, understood as a negotiation of interests that reaches an agreement that acquires the form of consensus, housing policy in Mexico is analyzed and, in a particular way, the implications at the local level through the agreements for the authorization processes of urban complexes in municipalities of the Metropolitan Area of the Valley of Mexico; this is done by taking up international and local documents on the topic, as well as through semi-structured interviews with municipal and state government officials. It is concluded that the post-political consensus is built from two dimensions, on the one hand, through regulations imposed by international organizations and the federal government and the tensions between different levels of government and real estate companies. In this way, the post-politics consensus can be understood from the superposition of discourses and practices at different levels, where the possibility of questioning politics and political projects around housing production is excluded
\end{abstract}

\section{Keywords}

Consensus, housing policy, Mexico City, post-political city 


\section{Introducción}

Desde finales del siglo XX, uno de los grandes problemas en términos habitacionales en México y, en América Latina en general, ha sido el déficit habitacional. Este puede ser entendido tanto en términos cuantitativos como cualitativos. Según el Banco Interamericano de Desarrollo (BID), el primero tiene que ver con los hogares que habitan en viviendas inadecuadas y sin posibilidades de reparación, junto con aquellos que comparten el mismo techo. Mientras que el segundo se refiere a los hogares que habitan en viviendas cuya tenencia es insegura, por ejemplo, sus paredes están construidas sobre la base de materiales de desecho (tales como hojas de palmera y cartón), tienen suelos de tierra, carecen de agua potable y saneamiento adecuado o tienen hacinamiento (tres o más personas por habitación) (Bouillon, 2012).

Ante este escenario, el papel del Estado en el contexto neoliberal ha sido de un fuerte intervencionismo, lejos de lo que los discursos neoliberales presuponen (Brenner et al., 2010; Harvey, 2007). El viraje del llamado Estado interventor al Estado facilitador representa una forma en la cual este participa en el mercado habitacional, sin embargo, hoy en día su función no solo es la de facilitar, sino también la de participar activamente en la financiarización del sector inmobiliario (Aalbers, 2019a; Aalbers y Brett, 2014), cuya creciente importancia se aprecia en el dinamismo del mercado inmobiliario habitacional. Con variaciones, se han implementado medidas del llamado modelo chileno de producción masiva de vivienda (Farfán, 2019; Sugranyes y Rodríguez, 2012), caracterizado por un Estado subsidiario y por un sistema crediticio como estructurador del acceso a la vivienda, dirigido tanto a la oferta como a la demanda.

Estas políticas se incorporaron en México hacia las últimas décadas del siglo XX y, de manera particular, a partir del inicio del presente siglo, dando como resultado que el parque de vivienda se incrementara de 21.942.535 viviendas en el año 2000 a 35.219.141 en 2020 (Instituto Nacional de Estadística y Geografía [INEGI], 2000, 2020). Una parte de este crecimiento es debido al mercado formal de vivienda económica, localizado en su gran mayoría en las periferias metropolitanas. Esta situación ha traído consigo diversas problemáticas - discutidas en varios trabajos-, vinculadas sobre todo con la movilidad (Graizbord y Acuña, 2007; Isunza, 2010a; Suárez y Delgado, 2010); temas ambientales (Isunza, 2010b; Lahoz, 2010); segregación y fragmentación urbana (Monkkonen, 2012; Monroy, 2015; Montejano et al., 2018; Salinas, 2016) y abandono de viviendas (López y Morales, 2018; López y Leal, 2012; Villavicencio y Duran, 2003); entre otros.

Las críticas al respecto - para el caso de ciudades latinoamericanas que se nutren de aportes de estudios urbanos críticos-destacan la relación entre empresas inmobiliarias y gobiernos locales en la construcción de vivienda, que entiende a esta como mercancía y destaca su valor de cambio por sobre su valor de uso. Un concepto usado para explicar dicha relación ha sido el de empresarialismo urbano (Harvey, 1989, 2001), el cual establece las actuales condiciones de la gestión gubernamental. Desde el análisis de la economía política resultan discusiones muy interesantes y sugerentes (Maddens y Marcuse, 2018). Entre otras cosas, se argumenta que la alianza entre el sector público y el sector privado parte de una estrecha relación en la cual muy difícilmente puede existir una participación del sector social. No obstante, resulta pertinente interrogarse o reflexionar en torno a este tema: ¿las políticas son diseñadas para mantener un orden social y no para atender los verdaderos problemas habitacionales?, ¿cómo son las formas locales que adquiere el consenso en la política de vivienda?

En este sentido, Žižek (2008) argumenta que, mediante la negociación de los intereses, se alcanza un acuerdo que adquiere la forma del consenso, es decir, el conflicto y el disenso están dominados hoy en día por el consenso, base de la post-política. En este orden de ideas, el objetivo del presente trabajo es analizar la construcción del consenso post-político en el cual hay una superposición de discursos y prácticas de diferentes niveles de gobierno con empresas inmobiliarias en el proceso de autorización de vivienda económica en la Zona Metropolitana del Valle de México (ZMVM), en donde se excluye la posibilidad de cuestionar la política de vivienda existente. 
Dado lo anterior, retomando las ideas de Swyngedouw (2011), se podría decir que la construcción masiva de vivienda en las periferias urbanas forma parte de una planeación urbana "despolitizada". A esto, Swyngedouw lo ha denominado la ciudad post-política, en el entendido que busca eliminar la disidencia y, más importante aún, excluye "lo político" (Swyngedouw, 2007, 2014a). Siguiendo esta línea, nuestra hipótesis es que la exclusión de lo político, entendido como la discusión sobre las condiciones actuales y las modificaciones de la política de vivienda, ha favorecido un esquema de producción masiva de vivienda económica en las periferias urbanas a partir de discursos y prácticas de consenso post-político. Este consenso se aprecia en dos dimensiones, por una parte, mediante la normativa "recomendada" (impuesta) por organismos internacionales como el Banco Mundial (BM) y el Banco Interamericano de Desarrollo (BID) y, posteriormente adoptada por el gobierno federal y; por otra parte, a partir de las tensiones entre los distintos niveles de gobierno (federal, estatal y municipal) y las empresas del sector inmobiliario, cuyos intereses políticos y económicos se sobreponen a las consecuencias económicas y sociales de la expansión de las periferias urbanas.

Para desarrollar esta hipótesis, el artículo se basa en una investigación llevada a cabo entre los años 2017 y 2018, en la ZMVM, en los gobiernos municipales de Huehuetoca, Tecámac y Zumpango, en donde se realizaron 12 entrevistas en profundidad a responsables de desarrollo urbano del gobierno del estado de México y de los gobiernos municipales. Las entrevistas buscaron conocer el proceso de autorización de los conjuntos urbanos, el origen de las decisiones -las cuales podrían o no estar basadas en normativas vigentes-, los problemas entre las diversas dependencias y escalas de gobierno, así como las decisiones detrás de los acuerdos a partir de ciertos intereses tanto políticos como económicos.

El artículo está organizado en tres apartados. La primera parte establece el contexto, el enfoque teórico y una intención de entender el diseño de políticas públicas en el marco del consenso neoliberal, para lo cual nos apoyamos en la noción de ciudad post-política. En la segunda parte se propone entender, con mayor detalle, la aplicación de la política de vivienda a partir del consenso post-político para América Latina como contexto internacional. En la tercera parte, se vincula la política de vivienda en el contexto post-político en el cual se excluye el disenso, pero se destacan las problemáticas que se generan en la toma de decisiones para la autorización de conjuntos urbanos en municipios del estado de México. Finalmente, en las reflexiones, se presentan los principales hallazgos en torno a las prácticas que desarrollan los funcionarios públicos en donde se negocian, se reinterpretan y se flexibilizan los marcos normativos de la política para mantener el consenso post-político.

\section{Metodología}

Este artículo argumenta la condición post-política en diversas escalas. En una primera etapa, desde la incidencia que tuvieron las medidas generales adoptadas por los organismos internacionales como el BM y el BID sobre las políticas nacionales de vivienda en México, en particular, hacia fines del siglo XX y principios del XXI. Para ello, se realizó una revisión de documentos internacionales y nacionales relativos al tema de vivienda, entre ellos, Housing. Enabling Markets to Work, editado por el BM, y el documento Programa Nacional de Vivienda representativo del nivel local. Además, se obtuvo información de la Secretaría de Desarrollo Urbano y Metropolitano del estado de México a partir de la cual se revelan cifras de autorización de conjuntos urbanos y vivienda, así como la identificación de las empresas inmobiliarias que participan.

A continuación, se presentan las negociaciones y las tensiones entre el gobierno del estado de México y los gobiernos locales en el proceso de autorización de los conjuntos urbanos, en donde los argumentos a favor de los beneficios generados (discursos) como las condiciones para flexibilizar o legitimar dicha dinámica inmobiliaria (prácticas) forman parte del consenso. Se eligió ejemplificar estas problemáticas en los gobiernos de Huehuetoca, Tecámac y Zumpango por representar tres de los municipios con mayor cantidad de producción de viviendas de las últimas dos décadas. De los 60 
municipios que forman parte de la ZMVM, entre el año 2000 y 2018 se autorizaron para su construcción 767.898 viviendas, de las cuales el 40,7 \% está en los tres municipios mencionados.

A partir de un enfoque cualitativo interpretativo se utilizó el diseño metodológico de la teoría fundamentada, la cual exige la elaboración de codificaciones y su comparación constante con la teoría propuesta con la intención de profundizarla (Corbin, \& Strauss, 2008). La principal técnica de recolección fue la entrevista semiestructurada en profundidad, posteriormente, estas se transcribieron y para su análisis se utilizó el software Atlas TI. No obstante, previo al análisis, fue necesario recurrir a fuentes secundarias para complementar la información y generar un marco contextual para dichos datos, además de los documentos relacionados con la normativa, los cuales permitieron indagar críticamente en los procesos de autorización de los conjuntos urbanos. Por medio de estos documentos ha sido posible discutir la construcción del consenso post-político, al mismo tiempo que conocer las tensiones existentes dentro de la construcción del consenso entre las diferentes escalas de gobierno.

\section{Construcción del consenso en la política de vivienda: la ciudad post-política}

"La polis está muerta. ¡Viva la ciudad creativa!” (Swyngedouw, 2007, p.1). Para definir lo qué es la ciudad post-política, Swyngedouw afirma que la polis está muerta y con ello se refiere a la antigua ciudad-estado griega, la cual se ha concebido como un espacio para el encuentro político y negociación democrática a partir de la disidencia y el desacuerdo. Mientras que, actualmente, se ha impuesto la racionalidad del consenso como lo aceptable "políticamente", de esta manera, la ciudad ha sido transformada en un espacio en donde impera el orden, los acuerdos y en donde se presumen escenarios de igualdad, de política democrática. En este contexto, la "politización” de los temas de debate público es relegada al dominio técnico y a los procedimientos de gobernanza que dejan la estructura política-económica intacta. Por ello, desde este enfoque se está construyendo una ciudad despolitizada o postpolítica (Swyngedouw, 2018).

Una de las principales críticas que se ha realizado al enfoque post-político se centra en que este muestra una limitación en su comprensión sobre la despolitización de la política formal (toma de decisiones a puerta cerrada). Principalmente, a través de la construcción de un relato estructuralista, basado en afirmaciones y descripciones a nivel de metadiscurso "omnipresente" e "inmutable" que no deja espacio para integrar las múltiples formas de agencias, instituciones y propuestas que interactúan en la producción de la ciudad, con lo cual termina socavando la comprensión académica como también las posibilidades de generar cambios, incluso, antes de que aparezcan (Beveridge, \& Koch, 2017).

En esta investigación, la revisión del consenso -en cuanto característica clave de la post-política- nos muestra las estrategias por medio de las cuales el disenso es suprimido en la política local. Por lo tanto, atender a sus formas locales y visibilizar cómo desde estas construcciones específicas los actores desarrollan y mantienen la actual política de vivienda mexicana es un paso adelante en esta formulación crítica. Desde este ámbito, se busca integrar discursos y prácticas institucionales que paradójicamente no son revisados y que, en este caso, dan cuenta de funciones que se organizan, se fuerzan y sobrepasan los límites de la normativa para intentar cumplir con el mandato político.

Para analizar la política de vivienda, para el caso específico del estado de México y de la (ZMVM), podemos empezar revisando las medidas que han incidido en las diversas escalas de gobierno e incluso en su relación con el ámbito internacional, es decir, con los diversos mecanismos y propuestas que han surgido en el impulso hacia el libre mercado para la desregulación del sector de la vivienda. Un caso paradigmático es el ya mencionado "documento político" Housing. Enabling Markets to Work, editado por el Banco Mundial (1993), el cual ha influido de manera directa en el diseño y en las reformas de la política de vivienda. 
A escala nacional, se puede observar que las modificaciones en la política de vivienda que han estimulado el mercado inmobiliario (con los Organismos Nacionales de Vivienda) en su apertura hacia el sector privado mediante programas particulares, han incidido fuertemente en la expansión urbana de las periferias. No obstante, sería un análisis limitado responsabilizar únicamente al gobierno federal sin considerar la participación del gobierno estatal y de los gobiernos municipales, quienes están presentes en tanto normativas para la autorización y construcción de vivienda y mediante la generación de Planes de Desarrollo Urbano. Sumado a lo anterior, esta relación de los tres niveles de gobierno resulta muy compleja, en el entendido que el artículo $115^{\circ}$ de la Constitución proporciona autonomía en la planeación urbana al gobierno municipal, sin embargo, el trabajo y la relación con el gobierno estatal son sumamente estrechos. Además, tampoco hay que olvidar que la influencia del gobierno federal no solamente está en las normativas y presupuestos, entre otros factores, sino también en las presiones directas, tal como se verá más adelante.

Los diversos documentos que se expresan a diversas escalas constituyen una intención política que se conjunta, en normas y reglamentos, como una política pública. De esta manera, en la política de vivienda que subyace al Programa Nacional de Vivienda en México se pueden apreciar las recomendaciones internacionales del Banco Mundial. Lo mismo ocurre en documentos normativos de subsidiaridad estatal del Ministerio de Vivienda de Chile (Decreto Supremo 155, creador del Fondo Solidario de Vivienda), entre otros. Lo importante de este instrumento (política) es la forma en la cual se crea, se acepta y también se aplica. En este contexto, Swyngedouw (2018) retoma estudios que discuten la llamada metagobernanza como gobernanza de primer y segundo orden, entendiendo por esta a las instituciones o acuerdos donde se definen los grandes principios de la gobernabilidad (por ejemplo, Unión Europea, Organización Mundial del Comercio, reuniones del G-89). Así, esta gobernanza de primer orden se asocia con la codificación y formalización de estos principios, mientras que la gobernanza de segundo orden se refiere al ámbito de la implementación real de políticas concretas.
Chantal Mouffe (2007) realiza una diferenciación entre lo político y la política, entendiendo por esta última el conjunto de prácticas e instituciones a través de las cuales se crea un determinado orden, el cual es producto de lo político, entendido a su vez como la dimensión de antagonismos constitutiva de las sociedades humanas:

"la política" se refiere al nivel "óntico", mientras que "lo político" tiene que ver con el nivel "ontológico". Esto significa que lo óntico tiene que ver con la multitud de prácticas de la política convencional, mientras que lo ontológico tiene que ver con el modo mismo en que se instituye la sociedad (Mouffe, 2007, pp. 15-16).

La dimensión óntica, por tanto, es la forma de materialización de los documentos de vivienda que se mencionan en una normativa que forma parte de la política. Mientras que la dimensión ontológica, será la manera por medio de la cual se construyen los argumentos a partir de la discusión y el disenso entre las diversas concepciones, es decir, lo político. Es muy pertinente la definición que proporciona Swyngedouw (2018) sobre la política que

se refiere a los juegos de poder entre los actores políticos, así como a las coreografías cotidianas de la formulación de políticas dentro de una configuración institucional y procedimental determinada en la que los individuos y los grupos sociales persiguen sus intereses (p. 40).

Para Mouffe (2007) lo que sucede actualmente es que lo político se expresa en un registro moral, "en lugar de una lucha entre 'izquierda y derecha' nos enfrentamos en una lucha entre el 'bien y el mal'" (p. 13), es decir, en juicios de valor, entre lo bueno y lo malo, donde el juicio de valor estará determinado por los poderes hegemónicos, a los que Žižek denomina tecnócratas ilustrados (2008). De esta manera, el disenso y la discusión que puede incidir en la modificación en la política de vivienda se evita al máximo, y si se genera una discusión, esta se desprecia al calificarla como una intención de "politizar" el tema, de manera que el juicio de valor predomina únicamente a partir de ciertos tecnócratas, funcionarios y empresarios del sector inmobiliario. 
En este sentido, Žižek (2008) argumenta que el conflicto entre las visiones ideológicas globales queda sustituido por la colaboración entre los tecnócratas ilustrados (economistas, expertos en opinión pública, políticos, etcétera) y los liberales multiculturalistas. Mediante la negociación de los intereses se alcanza un acuerdo que adquiere la forma del consenso más o menos universal, es decir, el conflicto y el disenso, que es lo que puede caracterizar lo político, está dominado hoy en día por el consenso, es decir, la post-política. De esta manera, el consenso en materia de vivienda se fundamenta en satisfacer las necesidades de mercado y no en entenderla como un derecho humano. Por ello, la política de vivienda se construye a partir de su importancia en el sector económico, en la industria de la construcción para la reproducción de capital y mediante la producción, la generación de empleo y derrama económica. Estos argumentos se sostienen en las diferentes escalas de gobiernos, donde la vivienda es considerada un medio, no un fin.

La construcción de consenso político, materializado en la política de vivienda, es elemental en la gestión empresarial, según explica Harvey $(1989,2001)$. La alianza del sector público y privado gira en este sentido, en donde los diferentes niveles de gobierno, que deberían procurar discusión y disenso político, operan de una manera gerencial para reproducir capital. $\mathrm{Al}$ respecto, Žižek menciona que es el crecimiento del enfoque o la aproximación gerencial (administrativa) a las tareas de gobierno, donde este es concebido cumpliendo una función gerente, el que lo priva de su auténtica dimensión política. La post-política rechaza la politización en el sentido de la Grecia clásica, es decir, la política como universalización metafórica de demandas particulares que apunta "a algo más" que la mera negociación de intereses. Los tiempos consensuales en que vivimos actualmente han eliminado así el genuino espacio político del desacuerdo (Žižek, 2002, citado en Swyngedouw, 2007, 2014b).

Por lo anterior, la política de vivienda se ha institucionalizado a partir de una suerte post-política, en tanto acuerdos y consensos para el mantenimiento de un orden.
La gran novedad de nuestra época post-política del "fin de la ideología" es la radical despolitización de la esfera de la economía: el modo en que funciona la economía (la necesidad de reducir el gasto social, etc.) se acepta como una simple imposición del estado objetivo de las cosas (Žižek, 2008, p. 110).

El consenso en materia de vivienda deja en claro la importancia económica. Por ello se buscaron (y reprodujeron) mecanismos para la acumulación de capital de empresas inmobiliarias mediante la subsidiaridad estatal, modelo aplicado desde principios del presente siglo, lo que generó una producción masiva de vivienda en las periferias urbanas.

\section{La construcción de consenso en materia de vivienda en el contexto internacional}

En América Latina se han implementado políticas de vivienda en las últimas décadas cuyas características se diferencian de manera particular según los contextos de cada país y ciudad, pero en lo sustancial se configuran siguiendo una lógica hegemónica que responde a la reproducción de capital. Las características, en términos generales, son: el Estado no participa de forma directa en la producción de vivienda; ha aumentado la vivienda en propiedad sobre la vivienda en alquiler; se ha reducido al mínimo la vivienda pública; se ha buscado erradicar los asentamientos irregulares y de no ser posible se han implementado procesos de "regularización" para introducirlos en el circuito del mercado formal; es el Estado quien sostiene el mercado formal mediante un sistema de créditos y subsidios tanto a la oferta como a la demanda y; más recientemente, se aprecia una "financiarización del Estado" (Aalbers, 2019b) gracias a la cual las empresas públicas y semipúblicas dependen cada vez más de los mercados financieros (ejemplo de ello son las instituciones públicas de vivienda las cuales para financiar los créditos para la demanda ingresan al mercado financiero a partir de la venta de la deuda, proceso conocido como titulización).

Estas condiciones que caracterizan la situación de la vivienda se han legitimado a partir de la generación de 
discursos oficiales que destacan que el mercado formal de vivienda favorece el crecimiento económico, ya que activa la industria de la construcción y sus diversas industrias asociadas, genera empleo, reduce el déficit habitacional y combate la expansión del mercado informal. Todo lo anterior constituye lo que se puede entender como el consenso de la política de vivienda para América Latina.

Mediante instituciones internacionales se pueden observar los lineamientos generales sobre los cuales se crea el consenso. El Banco Mundial, a partir del documento Housing. Enabling Markets to Work, estableció las condiciones para la producción y financiamiento de la vivienda. Dicho documento se inicia con un apartado titulado: "La vivienda en el sector económico", donde se afirma:

Se aconseja a los gobiernos que dejen de lado su anterior función de productores de vivienda y que asuman el papel de facilitadores de su administración en la totalidad del sector. Este cambio fundamental es necesario si se quiere dar a los problemas de vivienda una solución proporcional a su magnitud y si se quiere administrar al sector de vivienda como sector económico importante (Banco Mundial, 1993, p. 1).

Si bien es cierto es un documento que data 1993, aún permanecen vigentes sus lineamientos en los encuentros internacionales sobre el tema. No en vano, la misma institución (con apoyo de instituciones financieras internacionales) organiza el "Working across the housing value chain to deliver housing for all by 2030", con siete ediciones en torno al financiamiento de vivienda. Esta institución se ha encargado no solamente de emitir documentos con lineamientos sobre la vivienda sino además de otorgar financiamiento y créditos a los países.

Otra organización internacional que proporciona créditos para que los países se ciñan a las disposiciones emitidas por el Banco Mundial ha sido el BID, a partir de tres categorías de financiamiento para el sector público:
- préstamos de inversión los cuales financian bienes, obras públicas y servicios;

- préstamos de financiamiento especial para el desarrollo en caso de una crisis macroeconómica; y

- préstamos de apoyo a reformas políticas y/o cambios institucionales en un determinado sector, tal es el caso de la vivienda, para lo cual el país y el BID examinan y acuerdan dichas reformas o cambios ${ }^{1}$.

El consenso que se ha difundido sobre la necesidad de que sea el sector privado el responsable de la construcción de vivienda se mantiene como se puede apreciar en la siguiente cita:

El sector privado es visto cada vez más como una fuente potencial de productos y servicios valiosos para mejorar las viviendas (...); un número creciente de actores del sector privado y nuevas estrategias de negocios están emergiendo como respuesta al inmenso y sumamente atractivo mercado de la vivienda (BID, 2014, p. 6).

El documento del BID titulado Varios caminos hacia una vivienda comienza mencionando que la vivienda es una prioridad humana y un poderoso motor económico (2014). Estas dos condiciones han sido totalmente complementarias. Como prioridad humana se ha impulsado que el acceso a la vivienda sea mediante la propiedad privada, lo que se puede apreciar en el discurso de construir una sociedad de propietarios (Alexandri, \& Janoschka, 2018; Colau y Alemany, 2012; Rolnik, 2019). Con ello se "satisface" la necesidad de vivienda y, sobre todo, de crecimiento económico.

Esta construcción del consenso post-político, retomando a Swyngedouw, busca eliminar lo político en el entendido del disenso y el desacuerdo, pero además, el consenso se aprecia en la política a través de la normativa e instrumentos jurídicos como en la institucionalidad, tanto es así, que para el caso de México, el Banco Mundial conjuntamente con el BID han financiado la creación

1 En 2008 el organismo financiero internacional autorizó financiamientos por 8 mil millones de dólares para respaldar programas de construcción de vivienda en México (Cardoso, 2010). 
de instituciones públicas, como la Sociedad Hipotecaria Federal (SHF) surgida en 2001, con el objetivo de fomentar el desarrollo del mercado hipotecario secundario (Abhas, 2007), lo que constituye la metagobernanza de primer orden (Swyngedouw, 2018).

\section{México: seguimiento de los lineamientos internacionales}

El disenso y el conflicto (lo político) se mantiene ausente en la post-política, mientras que para Paulsen et al. (2019) aquello que constituye la gobernanza neoliberal se encuentra por todos lados, desde los movimientos sociales, activistas, periodistas, hasta en la academia. No obstante, la política institucionalizada excluye la participación social y la posibilidad de politizar (desde lo político) las decisiones. En los congresos legislativos, nacionales o locales, difícilmente se pueden discutir formas alternativas al problema de la vivienda que no sea considerarla como un sector importante para la economía y que su acceso sea en propiedad. Ante esta situación, las discusiones se refieren a los programas y las características que cumplen con esa visión, que ha sido impuesta y consensuada internacionalmente.

Como señalan diversos estudios (Boils, 2004; García, 2010; Puebla, 2002) México ha adoptado las medidas dictadas por el Banco Mundial y, como se mencionó anteriormente, creó la SHF para apoyar tanto la oferta como la demanda dentro del mercado formal de vivienda. En las últimas cuatro décadas, se han diseñado normativas y reglamentos que responden al consenso hegemónico sobre cómo debe ser entendido el tema de la vivienda, sin embargo, la exclusión de lo político ha dejado pocas alternativas que puedan ser desarrolladas desde la institucionalidad, sino solamente desde el activismo y los movimientos que discuten formas alternativas de acceder a esta.

\section{Zona Metropolitana del Valle de México como ciudad post-política}

Muchas discusiones, desacuerdos y problemas existen para la toma de decisiones desde la política, y en esto nos centraremos en este apartado, dando cuenta de la forma cómo se dan los acuerdos en la ciudad post-política, es decir, dentro del consenso hegemónico.

En una ciudad cuya zona metropolitana alcanza los 21 millones de habitantes, el tema de la vivienda es uno de los grandes problemas. Se podría pensar que la pobreza es un obstáculo para acceder a ella, debido a que se estima que esta es del 38,3 \% (Laboratorio para la ciudad, s.f.). Sin embargo, las estrategias para la reproducción del capital son tan diversas que los pobres representan un gran mercado, tal como lo recuerda Rolnik (2019) retomando una cita de Alphonse Allais: "Hay que buscar el dinero donde está: con los pobres. No es mucho lo que tienen, pero son muchos” (p. 206). No es solo la expresión de un escritor y periodista, pues las mismas instituciones internacionales así lo conciben. El BID argumenta que la base de la pirámide de la población (BDP) tiene poder adquisitivo.

La BDP representa alrededor de 4.000 millones de personas en todo el mundo. El World Resources Institute (WRI) ha estimado que esta población invierte cerca de US\$331.800 millones al año en viviendas, segundo gasto en importancia luego de compra y preparación de alimentos (Hammond et al., 2007). Se estima que la demanda de viviendas en la BDP es sólida y representa una proporción relativamente estable de los ingresos totales de la BDP. J.P. Morgan (2010) revela que la vivienda urbana asequible representa por lejos la oportunidad de inversión de mayor impacto dentro de los mercados de la BDP, comparado con los sectores de agua, salud, educación y microfinanzas. Este estudio estimó que 393 millones de hogares a nivel mundial pueden costear la mejora de viviendas, con ganancias anuales potenciales entre US $\$ 117.000$ millones y US $\$ 432.000$ millones, e inversiones de \$214.000-\$785.000 millones durante los próximos 10 años (BID, 2014, p. 18).

$\mathrm{Y}$, según este mismo documento del BID, los mercados de vivienda de la base de la pirámide de la población urbana de México alcanzan los USD\$16.000 millones en gastos anuales. 


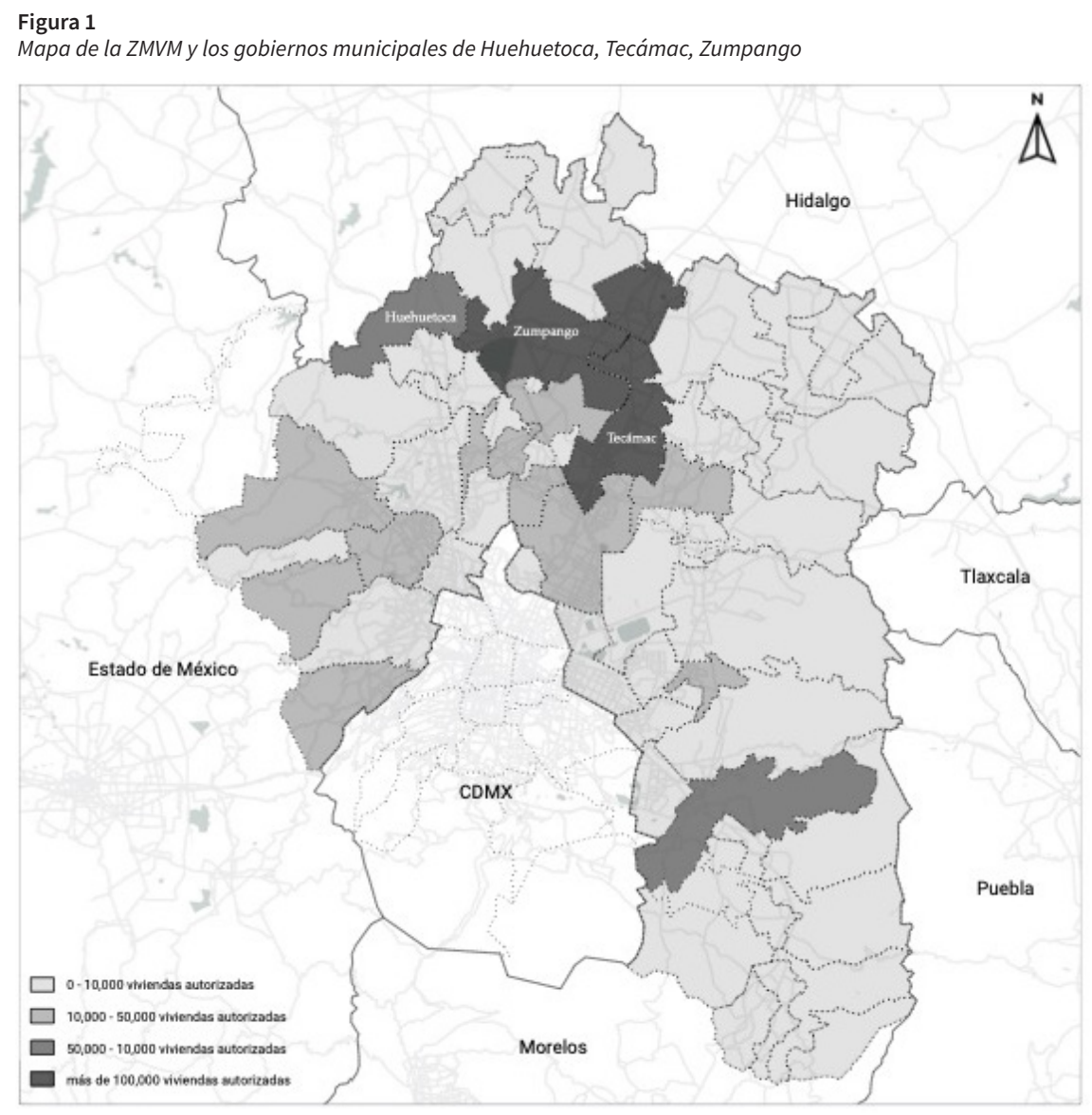

Nota. Mapa realizado sobre la base de información proveniente de la Secretaría de Desarrollo Urbano y Metropolitano del Estado de México.

Por las razones antes expuestas, la vivienda económica se convirtió en un vehículo idóneo para la reproducción de capital por parte de diversas empresas del sector inmobiliario. Así, desde el año 2000 hasta 2019 se autorizó la construcción de poco más de 760 mil viviendas, cuya gran mayoría se concentró en el norte y oriente de la ZMVM (Figura 1). Las disputas por este mercado se dan entre las empresas inmobiliarias, así como en los tres niveles de gobierno, tanto por los intereses que están en juego como por las competencias de cada uno. Estas disputas, en el ámbito de la implementación de las políticas, constituyen la metagobernanza de segundo orden (Swyngedouw, 2018).

\section{Imposición de consensos en los procesos de autorización de conjuntos urbanos}

Desde el enfoque de la post-política, podríamos interpretar la política habitacional como una especie de regla que gobierna organizando y distribuyendo funciones, actividades, personas, etc. En el caso de la autorización de conjuntos urbanos en la ZMVM consiste en un proceso normativo, donde desarrolladores y autoridades establecen un acuerdo para definir las características del conjunto a construir, los derechos y obligaciones del titular a cargo de la autorización y la documentación necesaria para acreditar la factibilidad del conjunto. Este proceso implica distintas fases que van desde la autorización de construcción, la construcción y fiscalización de las obras hasta el término del conjunto y su municipalización.

En el proceso de autorización se pueden identificar dos instancias de gobierno (estado de México y municipios) y una comisión sectorial (Comisión Estatal de Desarrollo Urbano y Vivienda, CEDUV). La generación de una propuesta proviene por parte de una empresa privada del sector inmobiliario. El municipio será el encargado de otorgar cambios de uso de suelo y licencia de uso de suelo y solicitar al desarrollador el equipamiento urbano 


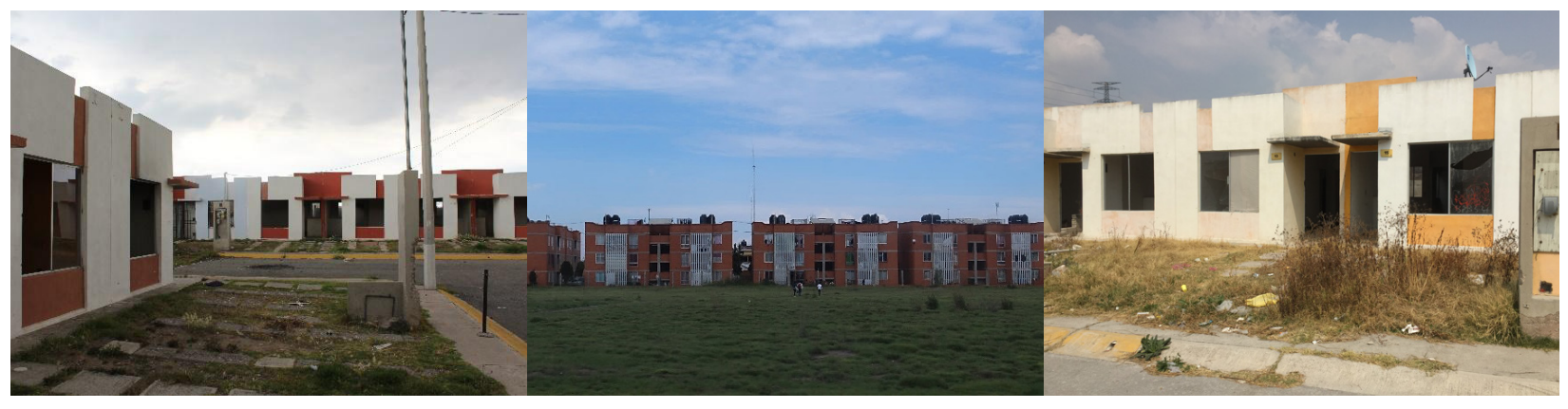

Nota. A la izquierda, conjuntos habitacionales en Zumpango; a la derecha en Huehuetoca.

regional. Además, el municipio otorga la factibilidad de dotación de servicios de agua potable y drenaje, y el gobierno del estado debe emitir una opinión técnica favorable de dicha factibilidad.

El gobierno del estado emite el dictamen de protección civil, de impacto y riesgo ambiental, dictamen de incorporación e impacto vial, aprobación del proyecto de lotificación y la constancia de no adeudo del correspondiente proyecto. Y el gobierno federal deberá emitir la factibilidad de suministro de energía eléctrica para el conjunto urbano de referencia. Una vez que se cumplen dichos estudios y dictámenes, el gobierno del estado expide la constancia de viabilidad del proyecto, y el gobierno municipal otorga la autorización. Con ello, se publica en el Diario Oficial del Estado de México y, solo en este momento, se puede iniciar la construcción del conjunto urbano (Salinas y Soto, 2019).

Sin embargo, en las entrevistas realizadas existen dos dimensiones a considerar en torno al esquema de autorización de conjuntos urbanos. La primera, como hemos descrito, se basa en la normativa existente, que contempla las fases para aprobar la construcción de conjuntos urbanos y las actuaciones de las distintas dependencias de gobierno. La segunda dimensión hace referencia a las prácticas que tensionan las actuaciones de los gobiernos y los funcionarios públicos, en donde la normativa se reinterpreta para consensuar y facilitar procesos conforme a los intereses de mercado. Ambas dimensiones del consenso permiten conocer, por una parte, cómo funciona la estrategia política desde la gestión y la racionalidad de la gobernanza, mientras que, por otra, cómo los conflictos que emergen al interior de la misma estructura son negociados por medio de mecanismos de poder local que flexibilizan procedimientos existentes, infringen marcos legales y coaccionan a los agentes institucionales para conseguir los objetivos.

El marco legal existente en los procesos de autorización de los conjuntos urbanos (factibilidades, dictámenes, recepciones) permite a los desarrolladores actuar conforme a lo que dicta la norma. Sin embargo, la normativa contrasta con la realidad de los municipios de la ZMVM, en donde se observan conjuntos urbanos no municipalizados, planeados y diseñados en completa precariedad. En este sentido, los problemas más recurrentes de la producción masiva de los conjuntos habitacionales en las periferias se asocian a la ausencia de infraestructura y equipamiento urbano, fuentes de empleo y servicios básicos, problemas relativos a falta de electricidad, abastecimiento de agua, etc., todo ello influye en el aumento de la vivienda en abandono (Figura 2). En muchos casos, estas problemáticas no se resuelven en el corto plazo como tampoco en el transcurso de los años. Los gobiernos locales para hacer frente a estas deficiencias no poseen estrategias definidas, más bien quedan sujetos a las voluntades de las autoridades estatales y federales quienes pueden asumir las responsabilidades de los proyectos inconclusos y, en ocasiones aún más extremas, continuar autorizando nuevas etapas de conjuntos de viviendas por las mismas empresas desarrolladoras.

Si bien la normativa es clara, las tensiones se hacen evidentes en la práctica entre las distintas dependencias de gobierno cuando se trata de determinar quién asume las responsabilidades en torno al fracaso de los conjuntos urbanos de las periferias urbanas. De acuerdo con los funcionarios del gobierno del estado, gran parte de las responsabilidades (permisos y cumplimiento de obligaciones de constructoras) recaen en el gobierno municipal. Para estos últimos, existen marcos de actuación 


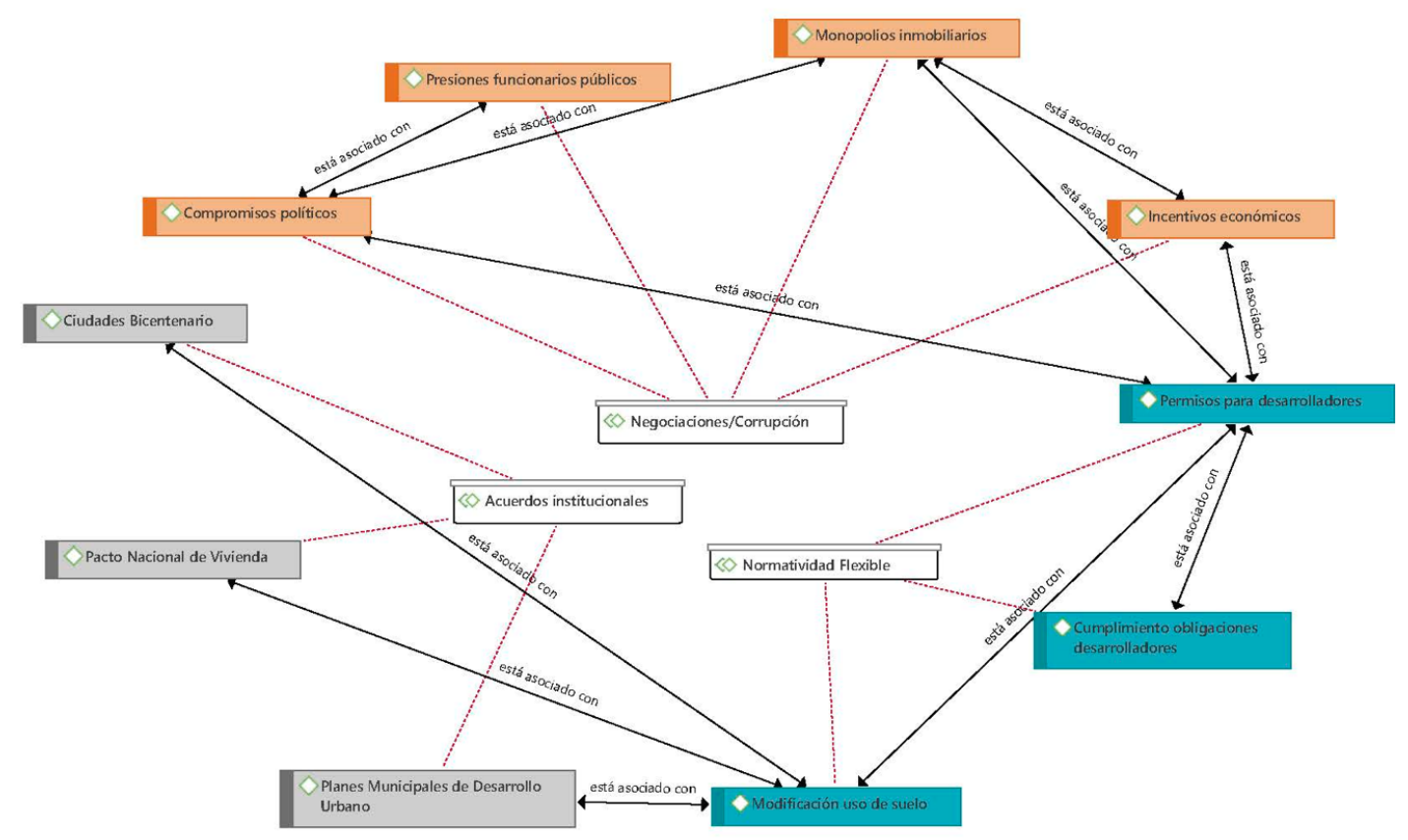

Nota. Esquema realizado a partir del trabajo de campo con ayuda del software Atlas ti.

que promueven la producción de la vivienda y ante los cuales no pueden hacer frente debido a las estructuras políticas que operan en sus territorios promoviendo la construcción masiva de vivienda.

En esta dimensión, las categorías extraídas de las entrevistas son reveladoras (Figura 3), en cuanto poseen la capacidad de mostrar los discursos y las prácticas que se tensionan en torno a los procesos de autorización de los conjuntos urbanos. Principalmente a través de:

- Acuerdos institucionales, en donde los funcionarios identifican una política que define la planeación en sus territorios y a la cual deben ajustar sus marcos de actuación. Esta se hace presente por medio de programas nacionales que propician la urbanización y la construcción masiva de viviendas de interés social.

- Normatividadflexible, se describen instrumentos que se flexibilizan en la práctica para permitir y facilitar proyectos constructivos, pese a la inviabilidad de los conjuntos o de la capacidad técnica-económica de los desarrolladores; al mismo tiempo que se aprueban permisos y concesiones en el cumplimiento de obligaciones de los desarrolladores evitando sanciones y traspasando obligaciones a municipios.

- Negociaciones/corrupción, en esta categoría se identifican los principales monopolios inmobiliarios presentes en los territorios, como también las prácticas y las negociaciones que intervienen en los procesos de autorización de los conjuntos urbanos, entre estas, compromisos de campaña, presiones a funcionarios, incentivos económicos.

Los funcionarios en las entrevistas hacen referencia a los acuerdos institucionales desde los cuales se realiza la planeación urbana y se dictan las pautas constructivas. Principalmente, la reflexión se dirige hacia la política de construcción masiva de vivienda, que fue impulsada en el año 2000 y que se fortaleció con acuerdos entre el gobierno federal y la Cámara Nacional de la Industria de Desarrollo 
y Promoción de Vivienda (CONADEVI) ${ }^{2}$, un ejemplo de ello es el Pacto Nacional de Vivienda ${ }^{3}$. Asimismo, se menciona el proyecto Ciudades del Bicentenario, impulsado en el año 2007, que tuvo como propósito promover zonas estratégicas de ordenamiento territorial, en donde se seleccionaron seis municipios, los cuales tendrían capacidad para concentrar infraestructura, sistema de transporte y comunicación para albergar a gran cantidad de población y actividades económicas. Sin embargo, este desarrollo - pensado como un modelo sustentable y competitivo- solo favoreció al sector de la construcción, generando una fallida planeación urbana, pero un exitoso mercado inmobiliario (Espinosa-Castillo, 2014).

Frente a estos lineamientos nacionales, los instrumentos locales como los Planes Municipales de Desarrollo Urbano se flexibilizan para permitir cambios de suelo favoreciendo el habitacional y el comercial. De esta manera, gobierno federal y estatal, así como el sector privado sentaron las bases - tanto normativas como con acuerdos de facto- para la construcción masiva de vivienda, mientras que los gobiernos municipales participaban también en dichos acuerdos por medio de la aprobación de proyectos inmobiliarios sin presentar oposición, al contrario, facilitando la autorización de conjuntos inviables.

Por otra parte, algunas de las dimensiones que fueron exploradas a través de las entrevistas a los funcionarios de gobiernos estatales, municipales y desarrolladores dan cuenta de prácticas en donde se reinterpretaron y se consensuaron los marcos normativos de la política (Figura 3). Como resultado, se obtuvo una normatividad flexible para facilitar el trabajo de desarrolladores, ya sea para que estos obtuvieran los permisos de construcción como para acordar los términos de entrega de proyectos, evitando sanciones y traspasando obligaciones a municipios. Estos acuerdos tuvieron por finalidad continuar con la producción de vivienda, pese a que las empresas no siempre reunieran las condiciones estipuladas por la normativa y los municipios tuvieran la capacidad para recibir la construcción masiva de viviendas.

El empresarialismo urbano, al cual ya se hizo referencia (Harvey, 1989, 2001), va más allá de la alianza entre el sector público y privado, ya que dentro o fuera del marco normativo, las empresas reproducen capital y se conforman monopolios inmobiliarios. En una entrevista, al tratar el tema en torno al monopolio de la desarrolladora Casas Geo en Zumpango, un funcionario público explicaba que esta empresa era la responsable del desarrollo urbano de esta zona:

Bueno, allí a nivel federal, me imagino yo, que deberán haber platicado lo referente a que cada empresa, este, se iba a hacer cargo de una ciudad. En ese caso a Geo le tocó Zumpango. (...) aquí vino una parte que se llama GEOPOLIS, pues para ponerle Geopolis pos tenía sentido, venía a hacer Geo, porque no era nada más la consultora sino era una empresa dedicada a la planeación de la ciudad. (Funcionario del gobierno del municipio de Zumpango, 2018).

Casas Geo, la empresa más importante de construcción de vivienda social en México, era encargada del desarrollo urbano de Zumpango. Durante los años 2000-2011 se autorizaron para su construcción 81.508 viviendas en este municipio, de las cuales esta empresa fue responsable del 70,7 \%. Cabe mencionar que la compañía entró en concurso mercantil en 2015 y fue liquidada tres años después. No obstante, a su director general se le autorizó en noviembre de 2019 la construcción de 1.158 viviendas (conjunto urbano "Las Palomas", llamado comercialmente "Privadas del Parque") en este mismo municipio (Acuerdo por el que se autoriza al arquitecto Luis Orvañanos Lascurain, el conjunto urbano de tipo

2 Institución surgida en el año 2002, la cual tiene como objetivo representar los intereses de sus afiliados ante los tres niveles de gobierno federal, estatal y municipal en materia de promoción y desarrollo de vivienda, así como con organismos internacionales de vivienda. Más información en canadevi.com.mx/

3 Hacia el año 2009 se firmó el Pacto Nacional de Vivienda el cual "contiene nueve puntos y varios objetivos, entre otros, la generación de 2,5 millones de empleos temporales, construir un millón de casas en el año y financiar con más de 180 mil millones de pesos la adquisición de vivienda popular" (Herrera y Cruz, 2009, s.p.). 
mixto (habitacional de interés social, comercial y de servicios) denominado "Las Palomas" comercialmente "Privadas del Parque", ubicado en calle San Francisco No. 1, Barrio de Santiago segunda sección, en el municipio de Zumpango, Estado de México de 2019).

Una alianza entre el sector público y privado se podría entender como un acuerdo en el cual ambos ganen, pero lo que se aprecia es que los beneficios se quedan para el sector privado, tanto para las empresas como para los funcionarios. Así coinciden algunos funcionarios del gobierno del estado de México al señalar "la delgada línea” en donde opera la influencia de los compromisos políticos establecidos entre autoridades y empresas (acuerdos de campaña), como también de los incentivos económicos que, pese a estar normados, se constituyen en "moneda de canje", permitiendo la aceptación de los permisos de construcción de los conjuntos (inversión de privados en beneficios comunitarios y/o infraestructura urbana a través de donaciones o aportes directos al fideicomiso del municipio). Como último recurso también se señalan las presiones a los funcionarios públicos, las que permiten que el proceso de autorización que podría durar hasta un año, apegado a las normas estatales y municipales, se reduzca considerablemente. En una entrevista se señala:

A lo mejor son inversionistas cercanos al gobernador, yo por decirte soy este: tengo un cargo medio, y simplemente recibo órdenes y los autorizan en tres días [refiriéndose a los conjuntos]. (Funcionario de la Oficina de Autorización de Conjuntos Urbanos, 2017).

En síntesis, el consenso de la post-política se puede entender a partir de la superposición de discursos y prácticas que excluyen la posibilidad de cuestionar la política, es decir, se suprime el disenso para mantener los acuerdos en los distintos niveles de gobierno. En los municipios analizados, la política de vivienda ha reproducido diversas problemáticas en torno al modelo de producción masiva. Un segundo nivel, es el consenso que se establece entre los gobiernos locales y las empresas inmobiliarias, el cual se fundamenta en prácticas que pueden estar sujetas a la normativa existente, como también pueden flexibilizar los marcos normativos de la política con tal de mantener el proyecto político nacional. Si bien, entre los distintos niveles de gobierno pueden existir tensiones en torno a la toma de decisiones (autorización de conjuntos urbanos), estas se resuelven por medio de negociaciones, presiones, corrupción, adaptación de instrumentos y normativas, los cuales se constituyen en el verdadero problema que debe enfrentar la política de vivienda en la escala local.

\section{Conclusiones}

Se pueden diferenciar dos dimensiones sobre el consenso construido en torno a la política de vivienda en los municipios de la periferia de la Ciudad de México, a partir del análisis de Huehuetoca, Tecámac y Zumpango. Primero, el que se instituye por cauces formales, en donde la normativa obedece a un consenso internacional, metagobernanza de primer nivel, en cuyo origen se planteó que el principal beneficiado sea el sector privado y, es el Estado el garante del funcionamiento del mercado formal de vivienda. El Estado, bajo el contexto neoliberal, tiene una activa participación en este mercado, en este sentido, se elaboran las políticas habitacionales desde el ámbito federal sin que exista una participación política desde los diferentes sectores de la sociedad. La imposición de este consenso post-político es la forma en la cual se consolida la dinámica del mercado formal de vivienda en México. Segundo, además de las normativas impuestas a nivel nacional, se crearon acuerdos políticos que responden a determinados intereses económicos, los que pueden ser acordes o no con los términos, condiciones y tiempos derivados de la normativa impuesta. En este sentido, las negociaciones del gobierno de turno con el sector inmobiliario muestran las diversas tensiones que se encuentran fuera de la normatividad existente y conforman la metagobernanza de segundo nivel.

En las últimas décadas, lo que se aprecia es una ausencia de discusión política en distintos espacios institucionales para cuestionar el proyecto político nacional en torno a la producción de vivienda. A pesar de que para el año 2013 se desarrolló una política que buscaba redensificar las áreas centrales (Programa Nacional de Vivienda 
2014-2018), la construcción de viviendas en las periferias urbanas continúa siendo la tendencia. De esta manera, se podría discutir - como se ha mostrado en numerosos estudios a nivel internacional- si se está cambiando de modelo de producción de vivienda y si se está centrando ahora en la redensificación. Sin embargo, este cambio de consenso busca la reproducción de capital, una vez agotado el modelo anterior, a partir de construcción en áreas revalorizadas de las ciudades. Es la modificación del consenso por una lógica estructural no por una discusión política, es una modificación de la post-política imperante. Por lo cual, resulta muy pertinente retomar los cuestionamientos de Maddens y Marcuse (2018) sobre los objetivos de la política de vivienda, más allá de los discursos políticos que enarbolan el combate a los problemas en torno a esta.

Si bien por medio de esta propuesta teórica podemos comprender el funcionamiento de la política de vivienda en la periferia de la Ciudad de México, ¿cómo romper con el orden y los acuerdos generados por la política habitacional en México? En este sentido, compartimos una de las críticas que se realiza al enfoque post-político en la medida en que el análisis por la estructura (consenso) no siempre discute la comprensión más plural de las agencias políticas que intervienen la construcción de la ciudad (Beveridge, \& Koch, 2017). Esto es una fuente de desafíos tanto para los investigadores/as, como para quienes gestionan y producen la ciudad y, en este caso, la política habitacional. Por lo tanto, teniendo este diagnóstico de inicio, ¿cómo incorporamos nuevas dimensiones que nos permitan un mayor entendimiento de lo que se concibe como político en la producción de la vivienda?, ¿cómo nos gustaría que fuera el acceso a la vivienda en nuestras ciudades?, ¿cuáles son los mecanismos que deberíamos desarrollar para que esto sucediera? Consideramos que estas preguntas deben ser enfrentadas con creatividad, tanto en el análisis como en el nivel de las propuestas, con tal de avanzar hacia alternativas que beneficien a la mayoría de la población, por sobre la acumulación de capital de empresas inmobiliarias que, mediante la subsidiaridad estatal, generan producción masiva de vivienda en las periferias urbanas.

\section{Referencias bibliográficas}

Aalbers, M. (2019a). Financial geography III: The financialization of the city: Geographies of tax. Progress in Human Geography, 44(3), 595-607. https://doi. org/10.1177/0309132519853922

Aalbers, M. (2019b). Financialization. En D. Richardson (Ed. en jefe.), The International Encyclopedia of Geography: People, the Earth, Environment, and Technology (pp. 1-14). Wiley.

Aalbers, M., \& Brett, C. (2014). Centring Housing in Political Economy. Housing, Theory and Society, 31(4), 373-394. https://doi.org/10.1080/14036096.2014.947082

Abhas, J. (2007). La vivienda popular en América Latina y el Caribe. Breve División de Operaciones para la Región de América Latina y el Caribe del Banco Mundial. http://documentos.bancomundial.org/curated/ es/198521468091484324/La-vivienda-popular-enAmerica-Latina-y-el-Caribe

Acuerdo por el que se autoriza al arquitecto Luis Orvañanos Lascurain, el conjunto urbano de tipo mixto (habitacional de interés social, comercial y de servicios) denominado "Las Palomas" comercialmente "Privadas del Parque", ubicado en calle San Francisco No. 1, Barrio de Santiago segunda sección, en el municipio de Zumpango, Estado de México de 2019 [Gobierno del Estado de México]. 19 de noviembre de 2019.

Alexandri, G., \& Janoschka, M. (2018). Who Wins and Who Loses in a in a Housing Crisis? Lessons from Spain and Greece for a Nuanced Understanding of Dispossession. Housing Policy Debate, 28(1), 117-134. https://doi.org/ $\underline{10.1080 / 10511482.2017 .1324891}$

Banco Interamericano de Desarrollo. (2014). Varios caminos hacia una vivienda. Nuevos modelos de negocio para la base de la pirámide en América Latina y el Caribe. Edición del autor. https://publications.iadb.org/es/ publicacion/16840/varios-caminos-hacia-una-viviendanuevos-modelos-de-negocio-para-la-base-de-la 
Banco Mundial. (1993). Housing. Enabling markets to work. With technical supplements. Edición del autor.

Beveridge, R., \& Koch, F. (2017). The post-political trap? Reflections on politics, agency, and the city. Urban Studies, 54(1), 31-43. https://doi.org/10.1177/0042098016671477

Boils, G. (2004). El Banco Mundial y la política de vivienda en México. Revista Mexicana de Sociología, 66(2), 345-367. https://doi.org/10.2307/3541460

Bouillon, C. (Ed.). (2012). Un espacio para el desarrollo: los mercados de vivienda en América Latina y el Caribe. Banco Interamericano de Desarrollo.

Brenner, N., Peck, J., \& Theodore, N. (2010). Variegated neoliberalization: geographies, modalities, pathways. Global Networks, 10(2), 182-222. https://doi.org/10.1111/ j.1471-0374.2009.00277.x

Cardoso, V. (15 de marzo de 2010). México, mayor receptor de préstamos del BID en 30 años, Periódico La Jornada, sección Economía. https://www.jornada.com.mx/2010/03/15/ economia/027n2eco.

Colau, A. y Alemany, A. (2012). Vidas hipotecadas. De la burbuja inmobiliaria al derecho a la vivienda. Angle Editorial.

Constitución Política de los Estados Unidos Mexicanos [Const.]. Artículo $115^{\circ}$ de 5 de febrero de 1917 (México).

Corbin, J., \& Strauss, A. (2008). Basics of Qualitative Research: Techniques and Procedures for Developing Grounded Theory (3rd ed.). Sage

Decreto Supremo N 155 / 14-09-200 de 2001 [Ministerio de Vivienda y Urbanismo de Chile]. Reglamenta el otorgamiento de subsidios habitacionales modalidad fondo concursable para proyectos habitacionales solidarios. 18 de julio de 2001.
Espinosa-Castillo, M. (2014). Megaproyecto urbano. La ciudad Bicentenario de Tecámac, México. Revista Bitácora Urbano Territorial, 24(2), 31-39. https://www.redalyc. org/pdf/748/74833911006.pdf

Farfán, X. (2019). Las políticas de vivienda social en Chile en un contexto de neoliberalismo híbrido. EURE (Santiago), 45(135), 5-26. https://doi.org/10.4067/ s0250-71612019000200005

García, B. (2010). Vivienda social 1940-1999: actores públicos, económicosysociales. Cuadernos de Vivienda y Urbanismo, 3(5) 34-49. https://revistas.javeriana.edu.co/index. php/cvyu/article/view/5527

Graizbord, B. y Acuña, B. (2007). Movilidad residencial en la Ciudad de México. Estudios Demográficos y Urbanos, 22(2), 291-335. https://doi.org/10.24201/edu.v22i2.1281

Harvey, D. (1989). From Managerialism to Entrepreneurialism: The Transformation in Urban Governance in Late Capitalism. Geografiska Annaler. Series B, Human Geography, 71(1), 3-17. https://doi.org/10.2307/490503

Harvey, D. (2001). Espacios del capital. Hacia una geografía crítica. Ediciones Akal.

Harvey, D. (2007). Breve historia del neoliberalismo. Ediciones Akal.

Herrera, C. y Cruz, Á. (14 de marzo de 2009). Ponen en marcha Pacto Nacional por la Vivienda. La Jornada. https:// www.jornada.com.mx/2009/03/14/politica/012n1pol

Instituto Nacional de Estadística y Geografía. (2000). Censo de población y vivienda 2000. https://www.inegi.org. $\mathrm{mx} /$ programas/ccpv/2000/

Instituto Nacional de Estadística y Geografía. (2020). Censo de población y vivienda 2020. https://www.inegi.org. $\mathrm{mx} /$ programas/ccpv/2020/ 
Isunza, G. (2010a). Política de vivienda y movilidad residencial en la Ciudad de México. Estudios Demográficos y Urbanos, 25(2), 277-316. https://doi.org/10.24201/edu.v25i2.1352

Isunza, G. (2010b). Efectos urbano-ambientales de la política de vivienda en la Ciudad de México. Espiral, 17(49), 129-159.

Lahoz, E. (2010). Reflexiones medioambientales de la expansión urbana. Cuadernos Geográficos, 46(1), 293-313. https:// revistaseug.ugr.es/index.php/cuadgeo/article/view/641

Laboratorio para la ciudad. (s.f.). Ciudad de México, un espacio de posibilidades. https://labcd.mx/contexto-tres/

López Álvarez, B. y Morales, F. (Coord.). (2018). Introducción general. Problemas urbanos y del territorio. En J. Cadena Roa, M. Aguilar Robledo y D. Vázquez Salguero (Coord. gnal.), Las ciencias sociales y la agenda nacional. Reflexiones y propuestas desde las ciencias sociales (Vol. IX) (p. 1). COMECSO. https://www.comecso.com/ ciencias-sociales-agenda-nacional/cs/issue/view/9/9

López, R. y Leal, J. (2012). Política de vivienda social en México: el caso de una colonia periférica de Monterrey. Cuadernos de Vivienda y Urbanismo, 5(10), 262-277. https://revistas.javeriana.edu.co/index.php/cvyu/ article/view/4133

Madden, D. y Marcuse, P. (2018). En defensa de la vivienda. Capitán Swing Libros.

Monkkonen, P. (2012). La segregación residencial en el México urbano: niveles y patrones. EURE (Santiago), 38(114), 125-146. http://dx.doi.org/10.4067/S025071612012000200005

Monroy, R. (2015). Fragmentación de escala y precarización. Referentes de la estructuración urbana convencional. Cad. Metropole, São Paulo, 17(33), 243-264. https://doi. org/10.1590/2236-9996.2015-3311
Montejano Escamilla, J. A., Caudillo Cos, C. A., \& Cervantes Salas, M. (2018). Vivienda de interés social, segregación residencial y accesibilidad: análisis de 121 conjuntos urbanos en el arco nororiente del Valle de México, 2001-2010. Estudios Demográficos y Urbanos, 33(1), 187-224. https://doi.org/10.24201/edu.v33i1.1639

Mouffe, Ch. (2007). En torno a lo político. Fondo de Cultura Económica.

Paulsen, A.; Rodríguez, L. e Hidalgo, R. (2019). Los espacios de furia. Política y ciudad a través de las luchas urbanas por la vivienda en Santiago de Chile (1990-2016). Cad. Metrop., São Paulo, 21(46), 763-782. https://doi.org/10.1590/22369996.2019-4604

Programa Nacional de Vivienda (2014-2018). http://www.dof. gob.mx/nota_detalle.php? codigo $=5342865 \&$ fecha $=30 /$ $\underline{04 / 2014}$

Puebla, C. (2002). Del intervencionismo estatal a las estrategias facilitadoras. Cambios en la política de vivienda en México (1972-1994). El Colegio de México.

Rolnik, R. (2019). Urban Warfare. Housing under the Empire of Finance. Verso.

Salinas, L. (2016). Política de vivienda en la Zona Metropolitana del Valle de México: entre la gentrificación y la segregación. Estudios Geográficos, CSIC, 77(280), 357-365. https:// doi.org/10.3989/egeogr.2016.i280.487

Salinas, L. y Soto, L. (2019). Política de Vivienda en México: entre la expansión y el retorno al centro. Investigaciones Geográficas, (99), 1-17. https://doi.org/10.14350/rig.59751

Suárez, M. y Delgado, J. (2010). Patrones de movilidad residencial en la Ciudad de México como evidencia de co-localización de población y empleos. EURE (Santiago), 36(107), 67-91. http://dx.doi.org/10.4067/ S0250-71612010000100004 
Sugranyes, A. y Rodríguez, A. (2012). El traje nuevo del emperador. Las políticas de financiamiento de vivienda social en Santiago de Chile. En J. Erazo (Coord.), Políticas de empleo y vivienda en Sudamérica (pp. 47-73). FLACSO; CLACSO.

Swyngedouw, E. (2007). The Post-political city. En BAVO (Ed.), Urban politics now. Re-imagining democracy in the neo-liberal city (pp. 58-76). NAI-Publishers.

Swyngedouw, E. (2011). Ciudadanos insurgentes: el retorno controvertido de lo político en las ciudades postdemocráticas. Espacios. Revista de Geografía, 7(14), 100-113. http://revistas.academia.cl/index.php/esp/ article/view/945

Swyngedouw, E. (2014a). Where is the political? Insurgent mobilisations and the incipient 'return of the political'. Space and Polity. Glasgow, 18(2), 122-136. https://doi. org/10.1080/13562576.2013.879774

Swyngedouw, E. (2014b). Interrogando la posdemocratización: reclamando espacios políticos igualitarios. Documentos y Aportes en Administración Pública, DAAPGE, 1(22), 7-43. https://doi.org/10.14409/da.v1i22.4251

Swyngedouw, E. (2018), Promises of the Political: Insurgent Cities in a Post-Political Environment. The MIT Press.

Villavicencio, J. y Durán, A. M. (2003). Treinta años de vivienda social en la Ciudad de México: nuevas necesidades y demandas. Script Nova. Revista Electrónica de Geografía y Ciencias Sociales, 7(146), 028. http://www.ub.edu/ geocrit/sn/sn-146(028).htm

Žižek, S. (2008). En defensa de la intolerancia. Ediciones Sequitur. 